\section{EMBRYRIDDLE \\ Aeronautical University}

SCHOLARLY COMMONS
International Journal of Aviation, Aeronautics, and Aerospace

\title{
Converting the Aircraft Passenger's Cabin to an Airship When There Is a Danger of Crash
}

Abouzar Bahari

PhD student of Payame Noor University, aboozar.bahari@gmail.com

Follow this and additional works at: https://commons.erau.edu/ijaaa

Part of the Aviation Safety and Security Commons

\section{Scholarly Commons Citation}

Bahari, A. (2020). Converting the Aircraft Passenger's Cabin to an Airship When There Is a Danger of Crash. International Journal of Aviation, Aeronautics, and Aerospace, 7(4). https://doi.org/10.15394/ ijaaa.2020.1516

This Concept Paper is brought to you for free and open access by the Journals at Scholarly Commons. It has been accepted for inclusion in International Journal of Aviation, Aeronautics, and Aerospace by an authorized administrator of Scholarly Commons. For more information, please contact commons@erau.edu. 
Converting the Aircraft Passenger's Cabin to an Airship When There Is a Danger of Crash

\section{Cover Page Footnote}

A.Bahari: PhD student of Physics, Payame-Noor University Email: aboozar.bahari@gmail.com 
Many different types of airlines have transported the people among the cities and countries in the world. However, although they have performed many appreciable services, they may face some faults/failures of their technical and/or safety systems during the flight that can endanger the people's life. In fact, the security of a flight is dependent on many parameters such as the airplane's technical systems (such as the wings, engines, hydraulic/ mechanical/ electrical/ fuel systems), safety systems such as the alarms, emergency auto systems, plus the pilot and control tower skills and health. If each of the mentioned factors does not perform its duty appropriately, a threatening incident may happen. A quick review of the airliners flight accident in the world indicates that unfortunately, failure of one or more of the aircraft mechanisms could cause a crash and lead to catastrophic losses. Therefore, we must accept that we are still far from $100 \%$ protection of the passenger's lives during the flights and still many people are worried during the flight.

Hence, up to now, many researches have worked to increase the aircrafts' safety. Some of them focus on the fuel type to lower its flammability (Federal Aviation Administration, 2008; Jones et al., 1952; National Research Council, 1997). Many other researches have worked to enhance the performance of the aircraft systems. Nevertheless, improving the airplane safety to guarantee the security of the people, both bodily and spiritually, is still of a high demand.

Airships are very similar to the air balloons but instead of the hot air, the lighter gases than the air such as hydrogen, helium, etc. is used to lift them. Hydrogen, due the lower cost and availability, was used in the commercial airships in 1930s to transport the people. However, since it is a flammable gas, some disasters like the Hindenburg accident happened (Moondance Films, 2002).At the same time, the much safer and faster airplanes had been entered to the air industry and thus, the airships were put aside completely and nowadays, they are rarely employedfor civil flight transportation.

In this research, we analyzed how to convert the aircraft passenger'scabin to the airship to float it in the air, when a serious incident threatens the people's lives.

\section{The Serious Faults that may Occur in an Aircraft During the Flight}

- Fault of the pilot or other crew persons (altitude computation, location of landing, airplane navigation, connection to the watchtower, etc.). As investigated, the most common cause of aviation accidents is human error, usually by the pilot (53\% of all accidents) or other persons (8\% of all accidents) (MH Sub I, 2020).

- $\quad$ Failures in some of the engines, causing an engine fire. 
- Failures in the mechanical/hydraulic/electrical/navigation/fuel/etc. systems.

- $\quad$ Damage of the wings (main part, flaps, etc.) and the airplane body due to the stresses applied and/or incomplete inspections (rules and regulations are not regarded). It should be noted that older airplanes have the higher potential to be faced with the failures because of the fatigue and creep stresses.

- Heavy storm/ very bad weather condition (huge fog, etc.).

Each of the mentioned faults or a collection of them together has a potential to be a serious problem and make the aircraft uncontrolled. Therefore, we must make a plan whenever the airplane becomes out of control.

\section{Design to Convert the Aircraft Passenger's Cabin to a Helium Airship}

When an aircraft encounters with a mentioned serious faults, taking it to the uncontrolled situation, which may lead to the crash/fire/explosion, etc., it is possible to convert the passengers plus the pilot cabin to a Helium airship. To do so, the current aircraft's design must be changed. Hence, the following steps would be anticipated:

1. After the serious damage occurs, the aircraft speed must be reduced. During this time, is available, the reverse trust system of the engines can be applied and/or a heavy parachute might be employed. If the aircraft speed is reduced too much, it will possibly face with tilting/ revolving and a possible free falling. Therefore, the conversion of cabins to the airship must performed before its forward momentum has stopped.

2. During step1, the gasoline storage must be jetted quickly into the air to release the airplane from the flammable gasoline and to make it lighter, as well.

3. To separate the isolated cabins from the main part of the aircraft body, two different design can be imagined:

I. The passengers and pilot cabin (joined together) is released from the aircraft when its speed is lowered down. In this way, the rear part of the body must include a door, which is capable of being opened when the cabin is going to be released as shown in the Figure 1. The release action can be performed via some small motors and rollers beneath the cabin. 


\section{Figure 1}

Passenger plus the pilot cabins are released from behind of the aircraft.

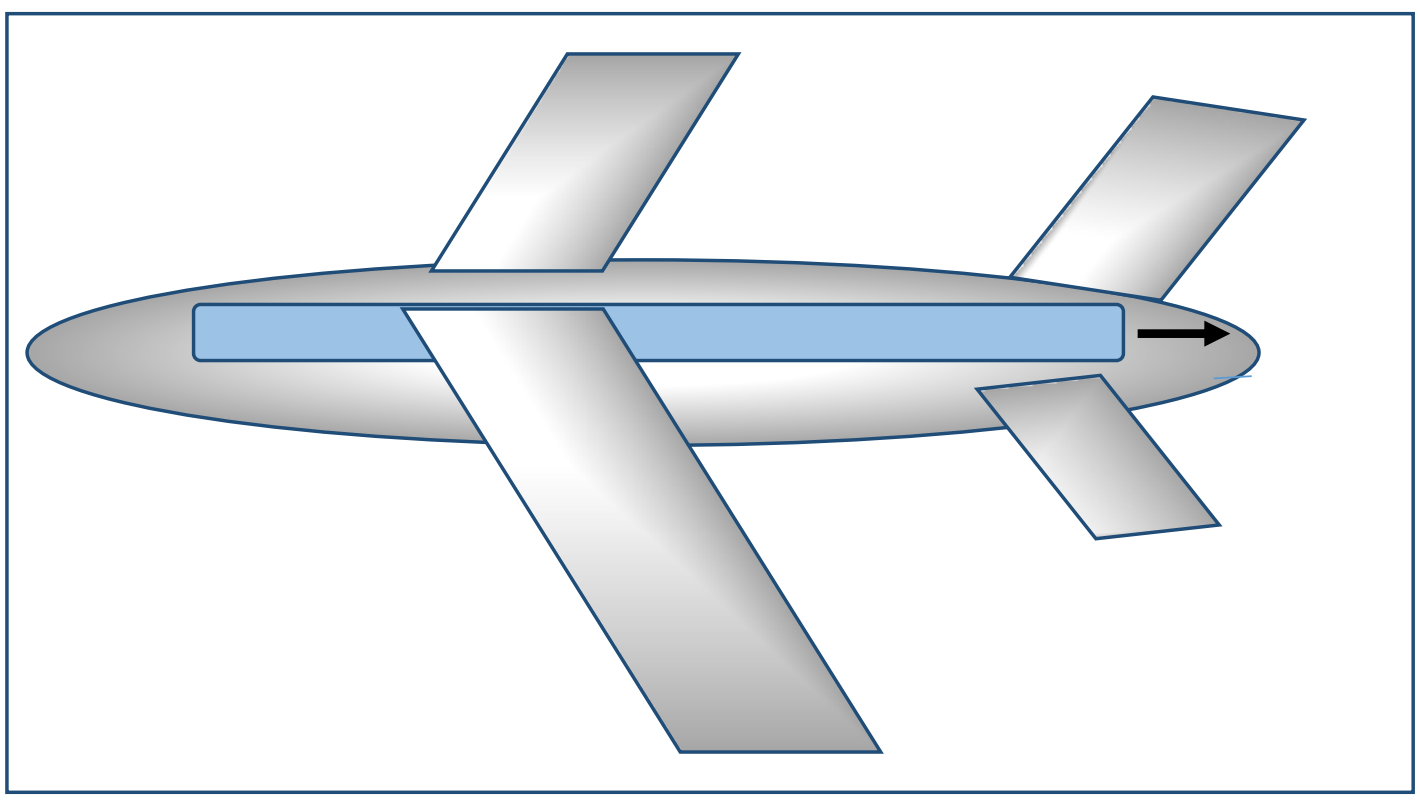

The cabin needs at least two parachutes, which must be opened immediately after the cabin is released. Then the balloons around the cabin must be filled with Helium quickly to float it in the air before it crashes.

II.Two hemispheres of the body shaft, being locked and screwed together, are separated from each other with the help of several hydraulic jacks, which are powerful enough to separate two hemispheres from each other completely, as illustrated in the Figure 2. The cabin needs at least two big parachutes to prevent it from free falling. 


\section{Figure 2}

Two hemispheres of the body shaft, being locked and screwed together, are separated from each other with the help of several hydraulic jacks.

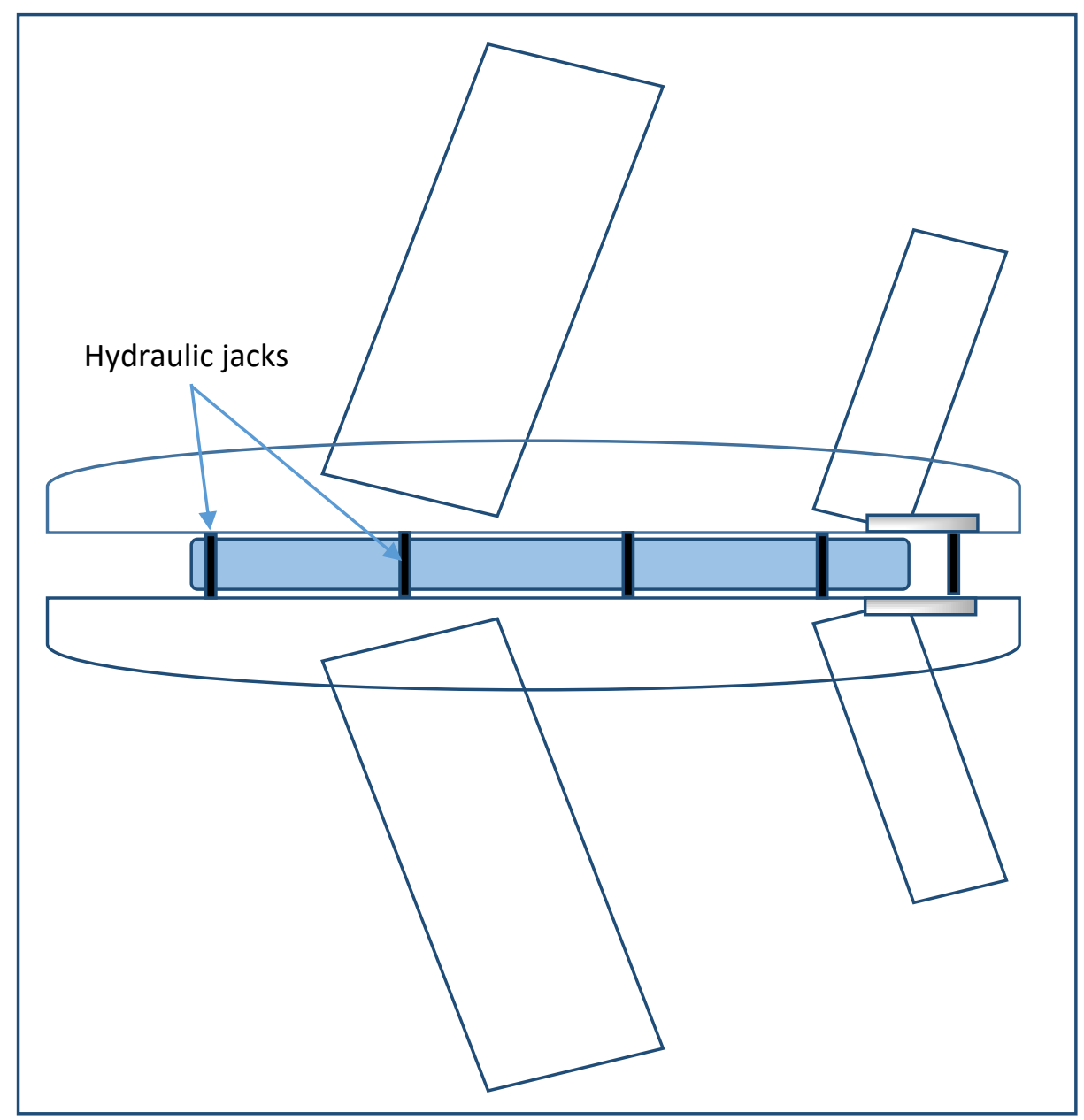

It should be noted that both of the designs I \& II requires some modifications in the today's aircrafts design to be adjusted with the new situations.

4. After the cabin is released from the aircraft's body and its two big parachutes are opened, the capsules, positioned on the cabin's roof must start to release the Helium gas inside the balloon to fill it completely. The balloon cloth is located on the cabin's roof, as well. To calculate how much volume 
of the Helium gas is required to float the passenger's cabin, we need to know the "lifting capacity" of the gas. Based on the literature, at the high altitudes, almost $1 \mathrm{~m}^{3}$ of the Helium gas is required to lift $1 \mathrm{~kg}$ of mass (Bormann \& Skutnik, 2020). If we consider a cabin with 100 numbers of passengers, it weighs almost 15 tons (weight of cabin + luggage). If the 5 tons weight of the big parachutes plus cloth of the balloon plus the empty helium capsules is considered, as well, almost $20000 \mathrm{~m}^{3}$ of the Helium is needed to lift the cabin and its accessories. If the cabin material is made of Carbon fiber or Carbon nano-tubes, the lighter cabin is expected (Yirka, 2012). However, since two or more parachutes are used to hang the cabin at first and besides, we just need the cabin to float in the air not to lift it up, it is expected that lower amount of Helium, i.e., $15000 \mathrm{~m}^{3}$ or even lower amount is required to float the cabin in the air. Therefore, the cloth envelope above the cabin should be filled with the Helium quickly. If we suppose an ellipsoid shape cabin with the dimension of length $(2 \mathrm{a})=50 \mathrm{~m}$, width $(2 \mathrm{~b})=5 \mathrm{~m}$, height $(2 \mathrm{c})=2 \mathrm{~m}$, the volume of cabin would be $V=\frac{4}{3} \pi a b c=262 \mathrm{~m}^{3}$. Thence, the balloon ellipsoid should be in the dimension of $\left(2 \mathrm{a}^{\prime}\right)=72 \mathrm{~m},\left(2 \mathrm{~b}^{\prime}\right)=20 \mathrm{~m},\left(2 \mathrm{c}^{\prime}\right)=20$ $\mathrm{m}$, making a volume $V=15048 \mathrm{~m}^{3}$. The net volume of the helium gas would be $V=15048-262=14786 \mathrm{~m}^{3}$ which is possibly enough to float the cabin in the air, as well. The area of an ellipsoid can be calculated from the formula $A=4 \pi \sqrt[p]{\frac{a^{p} b^{p}+a^{p} c^{p}+b^{p} c^{p}}{3}}$ in which $\mathrm{p}$ is a constant with the value of 1.6075. Thus, for the balloon envelope, the area (A) is computed to become around $3653 \mathrm{~m}^{2}$. This quantity of cloth weighs around three tons itself. Furthermore, two big parachutes also weigh around 1 ton. The Figure 3 illustrates the dimension of the Helium airship and the big parachutes of the cabin. 


\section{Figure 3}

The dimension of the Helium airship and the big parachutes of the cabin.

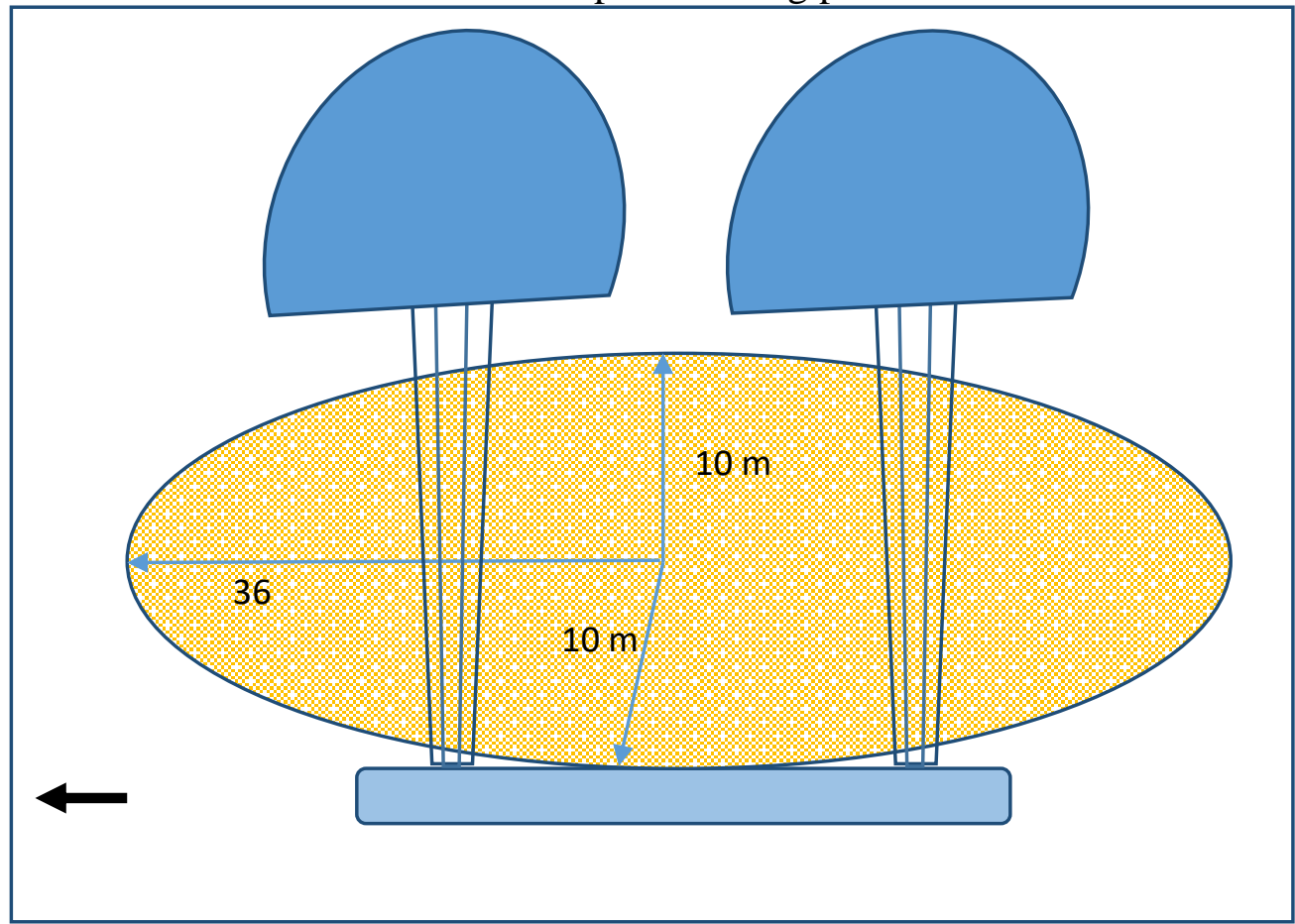

The envelope can be made of a combination of man-made materials: Dacron, polyester, Mylar, and/or Tedlar bonded with Hytrel. The high-tech, weather-resistant plastic film is laminated to a rip-stop polyester fabric. The envelope's fabric also protects against ultraviolet light (Botting, 1980; Lord $\&$ Kolesnik, 1982).

It should be taken into account that, the air pressure inside the cabin must not be changed during the whole process.

5. When the cabin is floated in the air, with the help of some small engines, positioned around the cabin, the pilot can navigate to find the best location for landing. Then he can reduce the amount of gas inside the balloon by a gas control system to land it in a safe location.

6. The main metal heavy body of the aircraft must employ a big parachute to prevent it from free falling. Otherwise, it may crash with a very high velocity and destroys some civilian areas. 


\section{Conclusions}

In this research, we have proposed a new aircraft design to convert the passenger's cabin to the airship to increase the safety of the people and crew whenever a disastrous situation is happened during the flight, which might be due the effect of many unwanted parameters. Today, whenever a serious accident happens, making the aircraft control questionable, there is a high probability that the aircraft will crash and lives will be lost. This is a concern to many people during the flight. Nevertheless, in today's era in which the humankind can send the spacecrafts to the other planets or near the sun, such worries about an airplane must be eliminated. By converting the aircraft's cabin to the airship, as explained in this research, the companies would be able to build the safest aircraft and protect the people's lives. People will prefer to travel with the new generation of airplanes and feel safer as they travel. This spiritually and bodily health guarantee will have a large global impact. Costumer confidence will increase. In addition, companies can potentially reduce insurance costs while increasing customer ticket sales. 


\section{References}

Bormann, A., \&Skutnik, S. (2020). HeiDas Uh - Ein HeissdampfaerostatMit Ultra-Heiss-Performance. Retrieved from https://web.archive.org/web/20110903091949/http://www.aeroix.de/filead min/user_upload/aeroix/redakteure/Dokumente_HeiDAS/HeiDAS_DGLR Kongress2005.pdf

Botting, D. (1080). The giant airships. Time-Life Books.

Federal Aviation Administration. (2008). Reduction of fuel tank flammability in transport category airplanes. Retrieved from https://www.federalregister.gov/documents/2008/07/21/E816084/reduction-of-fuel-tank-flammability-in-transport-category-airplanes

Jones, G. W., Zabetakis, M. G., Richmond, J.K., Scott, G., \&Furno, A.L. (1952). Research on the flammability characteristics of aircraft fuels, WADC technical report. Retrieved from https://apps.dtic.mil/dtic/tr/fulltext/u2/005805.pdf

Lord, V., \&Kolesnik, E. M. (1982). Airship saga: The history of airships seen through the eyes of the men, who designed, built and flew them. Blandford Press.

MH Sub I. (2020). Most common causes of aviation accidents. Retrieved from https://lawfirms.com

Moondance Films. (2002). The Hindenburg disaster: Probable cause [Documentary]. Retrieved from https://www.youtube.com/watch?v=Tq_geLlsXj4

National Research Council. (1997). Aviation fuels with improved fire safety. Retrieved from https://www.nap.edu/catalog/5871/aviation-fuels-withimproved-fire-safety-a-proceedings

Yirka, B. (2012). Aerographite: Ultra lightweight, flexible nanowall, carbon microtube material with outstanding mechanical performance. Phys.org. doi:10.1002/adma.201200491 